\title{
Women's outcomes following mixed-sex, women-only, and home-based cardiac rehabilitation participation and comparison by sex
}

Fiorella A. Heald ${ }^{1,2}$, Susan Marzolini ${ }^{1,2}$, Tracey J. F. Colella², Paul Oh ${ }^{1,2}$, Rajni Nijhawan ${ }^{2}$ and Sherry L. Grace ${ }^{1,2^{*}}$

\begin{abstract}
Background: Despite women's greater need for cardiac rehabilitation (CR), they are less likely to utilize it. Innovative CR models have been developed to better meet women's needs, yet there is little controlled, comparative data assessing the effects of these models for women. This study compared outcomes in women electing to participate in mixed-sex, women-only, or home-based CR, and a matched sample of men.

Methods: In this retrospective study, electronic records of CR participants in Toronto who were offered the choice of program model between January 2017 and July 2019 were analyzed; clinical outcomes comprised cardiorespiratory fitness, risk factors and psychosocial well-being. These were assessed at intake and post-6-month program and analyzed using general linear mixed models.

Results: There were 1181 patients (727 women [74.7\% mixed, 22.0\% women-only, 3.3\% home-based]; 454 age and diagnosis-matched men) who initiated CR; Cardiorespiratory fitness among women was higher at initiation of mixedsex than women-only (METs $5.1 \pm 1.5$ vs $4.6 \pm 1.3 ; P=.007$ ), but no other outcome differences were observed. 428 (58.9\%) women completed the programs, with few women retained in the home-based model limiting comparisons. There were significant improvements in high-density lipoprotein cholesterol $(P=.001)$ and quality of life $(P=.001)$, and lower depressive symptoms $(P=.030)$ as well as waist circumference $(P=.001)$ with mixed-sex only. $\mathrm{VO}_{2 \text { peak }}$ was significantly higher at discharge in mixed-sex than women-only (estimate $=1.67$, standard error $=0.63,95 \%$ confidence interval $=0.43-2.91$ ).
\end{abstract}

Conclusion: Participation in non-gender-tailored women-only CR was not advantageous as expected. More research is needed, particularly including women participating in home-based programs.

Keywords: Cardiac rehabilitation, Coronary heart disease, Outcomes, Quality of life, Women, Sex differences

\section{Introduction}

Cardiovascular Disease (CVD) is the leading cause of morbidity ( $13.5 \%$ of total disability-adjusted life years)

*Correspondence: sgrace@yorku.ca

${ }^{1}$ Faculty of Health, York University, Bethune 368, 4700 Keele Street, Toronto, ON M3J 1P3, Canada

Full list of author information is available at the end of the article and mortality (33\% of total deaths) for women globally [1]. Furthermore, women with CVD experience worse outcomes than men [2], with higher mortality rates following myocardial infarction, percutaneous coronary intervention (PCI), and coronary artery bypass graft (CABG) surgery [3, 4]. With regard to morbidity, women with acute coronary syndrome and those after coronary revascularization have longer hospitalizations and higher 
in-hospital mortality, and have 30\% more readmissions within 30 days after the index hospitalization compared to men [4].

Cardiac rehabilitation (CR) is an outpatient, comprehensive model of care for secondary prevention, which can mitigate the above burden. These programs are generally offered in clinical centres under supervision. CR has been shown to improve outcomes, including quality of life [5], hospital readmission rates, revascularization rates [6], and mortality [7]. While there are little randomized data on women's CR outcomes specifically [8], observational data suggests women may have even lower mortality than men where they fully participate $[9,10]$. Clearly, women are in great need of these services given their poorer cardiovascular outcomes, outlined above. Given the observational data on the benefits in women as well [11-13], the clinical practice guidelines for women with CVD recommend referral to CR [14].

However, CR utilization is sub-optimal [15], and even lower in women [16-18]. Women's CR barriers have been extensively studied [19, 20], and women-focused models have been developed to address them [21, 22]. These are programs where: (1) some or all components or sessions, (2) comprise all or mostly women (and staff), and/ or (3) content may be tailored to meet women's unique needs and preferences [23]. Moreover, home-based models (i.e., patients are supported remotely in their risk reduction) [24] may overcome women's common barriers such as transportation and time constraints due to family role obligations, and indeed some women prefer this approach $[25,26]$. Equivalent outcomes are observed with home-based and supervised programs, however most participants in the Cochrane review were men [27].

There are a limited number of studies regarding women-focused CR that include comparison groups, and even fewer comparing women in all 3 models, and to men [28]. Therefore, the objectives of this study were to compare: (1) cardiorespiratory fitness, (2) risk factors (i.e., blood pressure, lipids, tobacco use, and anthropometrics), and (3) psychosocial well-being (i.e., depressive symptoms and quality of life), in women between the three CR models. These outcomes are described in a matched sample of men in supervised CR for comparison purposes.

\section{Methods}

\section{Design and procedure}

This was a retrospective cohort study, with 4 comparison groups. Data used in this study were extracted from an electronic patient management record utilized across the University Health Network (UHN) Cardiovascular Prevention and Rehabilitation sites located in Toronto, Ontario, Canada, from January 1, 2017 to February 28,
2020 (only to March 31, 2019 for Toronto Western site as the program was shortened to 4 months at that time due to the wait list); data were extracted from pre and post-program.

\section{Setting}

UHN is an academic health sciences center comprised of several hospitals, with an advanced cardiac program. There are 2 CR programs (at Toronto Western Hospital [acute care centre] and Toronto Rehabilitation Institute [large outpatient centre]) and 1 satellite at a local university; data from the satellite were not included as many participants are stroke patients and the program is of shorter duration. The median wait time to start the programs is 42 days [29]. Staff at both centers are multidisciplinary, with extensive experience.

Before starting the program, every patient completes an intake assessment, including questionnaires (e.g., depressive symptom screens, medical history, health behaviours), risk factor assessment (e.g., body composition), a consultation with a program physician (e.g., medication review). A follow-up appointment for an exercise stress test is scheduled, most commonly on a treadmill using a modified Bruce protocol. All data are entered into the electronic record. Patients are reassessed at the end of their program (after 6 months), inclusive of risk factor assessment and functional capacity testing.

\section{Models}

At both centres, at the time of the exercise stress test, patients are given the option to choose between the supervised program at the centres or the home-based program, and women have the additional option of the supervised women-only program. Model selection is primarily based on patient preference rather than clinical criteria, although patients are encouraged to enroll in a class that best suits their medical condition.

Also at both centres, both the supervised mixed-sex and women-only models offer a comprehensive program that consists of structured exercise, patient education, risk factor management, dietary as well as psychosocial counselling, in addition to other components as needed. After the intake assessment, there are weekly classes onsite over 6 months ( 25 sessions total); each class lasts approximately $90 \mathrm{~min}$.

Aerobic exercise is individually prescribed, to be performed 5 days per week. Initial training intensity is based on patients' exercise stress test, in accordance with the American College of Sports Medicine guidelines [30]. Target heart rate is calculated using the anaerobic threshold and heart rate reserve, with an exercise intensity range of $60 \%$ to $80 \%$; the intensity of exercise may be adjusted to achieve an 11-15 rating of 
perceived exertion [31]. During CR, participants walk/ jog on the track (Toronto Rehab only) or use treadmills and bicycles. Prescription progression is considered approximately every 2 weeks as exercise specialists deem fit, with the goal of increasing to 30-60 min per session. As most patients are on a beta-blocker, exercise intensity is monitored using perceived exertion (heart rate used as a guideline).

Patients are prescribed resistance training unless contraindicated or limited by comorbidities. Resistance training is prescribed $2-3$ sessions per week, comprising 7-10 upper and lower body exercises. Initial weight loads of $60 \%$ of 1-repetition maximum are used; one set of 10 repetitions is prescribed initially and patients progress to 2 sets and increase to 15 repetitions before weights increase [32]. Handheld dumbbells, resistance bands, and/or body weight are used. All patients are encouraged to document their exercise in an exercise diary that is reviewed by the exercise specialists weekly.

The patient education program is evidence-based, and delivered in a group setting in conjunction with each visit (https://www.healtheuniversity.ca/en/cardiaccol lege/Pages/default.aspx) [33]; patients are encouraged to read the corresponding booklet in advance and bring it to each session, where the patients are engaged in the education through adult learning principles.

Participants are screened for depressive symptoms, with those screening positive being referred to the program social worker or psychologist. All participants are offered a group stress management program, and 1-1 sessions with the registered dietitian. Aside from women being the only sex participating in the women-only program and that examples during patient education are tailored to the audience, all aspects of the program are consistent with supervised mixed-sex program (i.e., not gender-tailored content).

The home-based model involves a personalized program to be followed at home [34], supported by online patient education. In addition to the on-site assessments as outlined above, home-based patients also come to the centre for a one-on-one orientation, as well as an aerobic exercise trial and resistance training instruction at the start of the program. Patients have weekly telephone consultation for the first 3 months, and less frequent telephone consultation thereafter through month 6 (same overall program duration as supervised models), each lasting for $15 \mathrm{~min}$ on average, for a total average of 15 calls. Patients come on-site for stress management and/ or 1-1 dietary counselling as per their needs, and for their exit assessment as in the supervised programs (i.e., program completion). Otherwise, exercise prescription and progression as well as other components are synonymous with the supervised models and across the two centres.

\section{Participants}

To be included in the program, patients had to be 18 years or older with at least one of the following indications: coronary artery disease (CAD)/acute coronary syndrome, spontaneous coronary artery dissection, atrial fibrillation, adult congenital heart disease, cardiomyopathy, following cardiac interventions (i.e., PCI, CABG, valve intervention/surgery, implantable rhythm device, aneurysm repair, and ablation), and those at risk for developing CAD or CVD (minimum of 3 modifiable cardiac risk factors, including diabetes, hypertension, dyslipidemia, current/recent tobacco use, depression, family history).

The program has separate classes for patients with stroke, heart failure, heart transplant, diabetes, and breast cancer, which were not considered in this study. Those who had exercise-limiting medical issues such as pulmonary disease, were at significant risk of a fall, and with significant cognitive and/or uncontrolled serious mental health (i.e., not anxiety, etc.) issues which would impede safe participation were excluded from the program.

Study-specific inclusion criteria were graduated female patients who attended at least 1 on-site exercise session for supervised models and 1 telephone consultation for the home-based model; males who were in the supervised model were eligible for matching. Patients were considered to have completed the program if they did not fail to attend 2-3 consecutive CR sessions (telephone consultations for home-based model) without notice and respond to communication attempts made by the program, and completed the post-program assessments [35].

\section{Measures}

Sociodemographic (e.g., age at enrollment, marital status, language spoken, highest educational attainment, occupational status, travel time to CR centre; data on ethnocultural background were not available) and some clinical characteristics (e.g., tobacco use: current, former/never) were obtained from questionnaires that patients completed prior to program initiation. Clinical data were also extracted from the referral form (e.g., cardiac event/procedure) and initial assessments.

\section{Outcomes}

Outcomes were measured at intake and discharge assessments. Cardiorespiratory fitness was operationalized as $\mathrm{VO}_{2 \text { peak }}$ (volume of oxygen consumed per unit of time [30], expressed in $\mathrm{mL} / \mathrm{kg} / \mathrm{min}$; Toronto Rehab) 
or metabolic equivalent of task (METs; Toronto Western), which were obtained during the graded exercise stress test. Given the measurement error associated with the latter, while results from the Toronto Rehab cardiopulmonary assessments were converted to METs so results across both sites could be grouped, $\mathrm{VO}_{2 \text { peak }}$ was also extracted and compared in the Toronto Rehab participants.

With regard to risk factors, systolic blood pressure (SBP) and diastolic blood pressure (DBP), measured in $\mathrm{mmHg}$, were assessed at Toronto Rehab using microphone-assisted Korotkoff auscultation by a cardiopulmonary technologist or attending physician prior to the cardiopulmonary exercise test (position depending on the exercise test modality). At Toronto Western, $\mathrm{BP}$ was assessed pre and post via manual sphygmomanometer. The initial BP target in adults is $<140 \mathrm{mmHg}$ for SBP and $<90 \mathrm{mmHg}$ for DBP [36, 37].

Lipid profile was recorded from bloodwork results from patient's referral information or standard medical laboratory report where available (not all patients went for the test despite provision of requisition post-program). The American College of Cardiology recommends a low-density lipoprotein cholesterol (LDL-C) goal of $1.8 \mathrm{mmol} / \mathrm{L}$ for very high-risk patients, such as those in the current cohort with a history of multiple major atherosclerotic CVD events or 1 major atherosclerotic CVD event and multiple high-risk conditions [38]. Waist circumference measurements (in centimeters) were taken horizontally around the abdomen at the narrowest part of the torso between the iliac crest and the xiphoid process (or at the level of the iliac crest if narrowest part is not available) at end expiration in standing position using a tape measure; a cutoff of $\geq 88 \mathrm{~cm}$ in women and $\geq 102 \mathrm{~cm}$ in men [38] was used as target. Body mass index was defined as body mass, measured using the InBody 520 body composition analyzer (Biospace Co., Ltd., Seoul, South Korea), divided by the square of body height $\left(\mathrm{kg} / \mathrm{m}^{2}\right.$; stadiometer). Tobacco use is outlined above.

In terms of psychosocial well-being, depressive symptoms were self-reported using the 20 -item validated Centre for Epidemiologic Studies-Depression (CES-D) scale (only administered at Toronto Rehab) [39]. Where 4 or less item scores were missing, the mean score on completed items for that participant was used; where more items were not completed the data were not used. Scores range from 0 to 60 ; higher scores indicate greater depressive symptoms, and scores $\geq 16$ indicate suspected depression. Quality of life was measured with Cantril's ladder [40]. Patients are presented with a picture of a ladder with steps numbered from 0 at the bottom, representing the worst possible life, to 10 at the top, representing the best possible life for them. Patients were asked on which rung of the ladder they felt they personally stood at the present time.

\section{Statistical analysis}

Statistical analyses were performed using IBM SPSS Statistics for Macintosh, version 26.0, with statistical significance defined as $P<0.05$.

First, descriptive statistics were used to describe the characteristics of participants at CR intake, by model. Results were reported as numbers and percentages (\%) for categorical variables and mean \pm standard deviation (SD) for continuous variables. Variables were scrutinized to determine whether they were normally distributed; non-parametric tests were applied where they were not, as outlined below.

For the sex comparisons, women were first matched to men based on age (1-2 years interval) and cardiac intervention (CABG and non-CABG) using the Case-Control Matching procedure without replacement. Then, differences in any sociodemographic and clinical characteristics at intake as well as wait time between matched men and women in the mixed-sex model were compared using the Mann-Whitney $\mathrm{U}$ test and chi-square tests, as appropriate (age and sex were different before matching, with women older and less often having CABG).

Pre-CR sociodemographic and clinical characteristics of women retained in the program versus lost to follow-up (i.e., did not complete any post-program assessments) were compared using the Mann-Whitney U test or chi-square as applicable. Then, within-subject outcome changes from intake to discharge in each CR model (women and men) among completers were explored using paired-samples t-test for continuous measures, and McNemar's test for analysis of tobacco use. Finally, to assess between-group changes, for continuous outcomes, general linear mixed models were performed with the clinical outcome as the dependent variable, CR model (or sex in the women and men comparison) and timepoint as fixed effects parameters, and intercept as random effects parameter; the women-only model and men were used as reference categories. Tobacco use could not be compared between CR models due to low numbers.

\section{Results}

\section{Cohort characteristics}

The female cohort during the period of study comprised 543 participants in the supervised mixed-sex, 160 in supervised women-only, and 24 in the home-based model; model choice is considered elsewhere [41]. The matched cohort comprised 454 women and 454 men in supervised mixed-sex; thus, there were 1181 participants 
Table 1 Participant's sociodemographic and clinical characteristics pre-program by model and sex

\begin{tabular}{|c|c|c|c|c|c|}
\hline & \multirow{2}{*}{$\begin{array}{l}\text { Men* } \\
\text { Mixed-sex } \\
N=454\end{array}$} & \multicolumn{4}{|l|}{ Woment } \\
\hline & & $\begin{array}{l}\text { Mixed-sex } \\
\mathrm{N}=543(74.7 \%)\end{array}$ & $\begin{array}{l}\text { Women-only } \\
\mathrm{N}=160(22.0 \%)\end{array}$ & $\begin{array}{l}\text { Home-based } \\
\mathrm{N}=24(3.3 \%)\end{array}$ & $\begin{array}{l}\text { Total } \\
N=727\end{array}$ \\
\hline \multicolumn{6}{|l|}{ Sociodemographic } \\
\hline Age & $66.8 \pm 11.8$ & $66.7 \pm 12.1$ & $68.1 \pm 12.1$ & $61.3 \pm 16.9$ & $66.9 \pm 12.3$ \\
\hline Marital status (\% married/common-law) & $290(82.2 \%)^{* * *}$ & $257(67.8 \%)$ & $67(63.2 \%)$ & $9(60.0 \%)$ & $333(66.6 \%)$ \\
\hline Highest educational attainment (\% $\geq$ high school) & $226(93.8 \%)$ & $299(92.3 \%)$ & $79(94.0 \%)$ & $12(100.0 \%)$ & $390(92.9 \%)$ \\
\hline Language spoken (\% English) & $313(95.1 \%)$ & $411(96.3 \%)$ & $111(98.2 \%)$ & $20(100.0 \%)$ & $542(96.8 \%)$ \\
\hline \multicolumn{6}{|l|}{ Occupational status } \\
\hline Retired/no formal employment & $147(54.9 \%)$ & 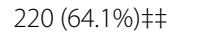 & 74 (80.4\%)㧊 & $6(54.5 \%)$ & $300(67.3 \%) \dagger$ \\
\hline Full-time/part-time/ modified/restricted duties & $101(37.7 \%)$ & $103(30.0 \%) \neq$ & 16 (17.4\%)‡ & $4(36.4 \%)$ & $123(27.6 \%) \dagger$ \\
\hline Other (e.g., disability) & $20(7.5 \%)$ & $20(5.8 \%)$ & $2(2.2 \%)$ & $1(9.1 \%)$ & $23(5.2 \%)$ \\
\hline Travel time to CR centre (\% 0-30 min) & $124(63.3 \%)$ & $143(61.1 \%)$ & $34(58.6 \%)$ & $2(40.0 \%)$ & $179(60.3 \%)$ \\
\hline \multicolumn{6}{|l|}{ Living situation } \\
\hline With spouse/partner & $212(70.2 \%)^{* * *}$ & $201(50.9 \%)$ & $44(43.6 \%)$ & $11(68.8 \%)$ & $256(50.0 \%)$ \\
\hline Alone & $41(13.6 \%)^{* * *}$ & $123(31.1 \%)$ & $37(36.6 \%)$ & $4(25.0 \%)$ & $164(32.0 \%)$ \\
\hline With family/friends/others & $49(16.2 \%)$ & $71(18.0 \%)$ & $20(19.8 \%)$ & $1(6.3 \%)$ & $92(18.0 \%)$ \\
\hline \multicolumn{6}{|l|}{ Clinical characteristics } \\
\hline \multicolumn{6}{|l|}{ Referral event/procedure§ } \\
\hline $\mathrm{PCl}$ & $228(50.6 \%)^{* * *}$ & $185(34.4 \%)$ & $54(34.0 \%)$ & $7(31.8 \%)$ & $246(34.2 \%)$ \\
\hline Valvular heart disease & $34(7.5 \%)^{*}$ & $62(11.5 \%)$ & $20(12.6 \%)$ & $1(4.5 \%)$ & $83(11.5 \%)$ \\
\hline CABG & $41(9.1 \%)$ & $50(9.3 \%)$ & $21(13.2 \%)$ & $1(4.5 \%)$ & $72(10.0 \%)$ \\
\hline Stroke/TIA & $40(8.9 \%)$ & $52(9.7 \%)$ & $13(8.2 \%)$ & $2(9.1 \%)$ & $67(9.3 \%)$ \\
\hline Primary prevention & $8(1.8 \%)^{* * *}$ & $41(7.6 \%)$ & $10(6.3 \%)$ & $1(4.5 \%)$ & $52(7.2 \%)$ \\
\hline Arrhythmia/Rhythm device & $21(4.7 \%)$ & $35(6.5 \%)$ & $14(8.8 \%)$ & $0(0.0 \%)$ & $49(6.8 \%)$ \\
\hline Heart failure & $16(3.5 \%)$ & $22(4.1 \%)$ & $3(1.9 \%)$ & $1(4.5 \%)$ & $26(3.6 \%)$ \\
\hline Angina pectoris (stable/unstable) & $25(5.5 \%)$ & $21(3.9 \%)$ & $3(1.9 \%)$ & $1(4.5 \%)$ & $25(3.5 \%)$ \\
\hline Cardiomyopathy & $7(1.6 \%)$ & $17(3.2 \%)$ & $4(2.5 \%)$ & $3(13.6 \%)$ & $24(3.3 \%)$ \\
\hline $\mathrm{Ml}$ & $3(0.7 \%)^{* *}$ & $17(3.2 \%)$ & $4(2.5 \%)$ & $1(4.5 \%)$ & $22(3.1 \%)$ \\
\hline PVD & $18(4.0 \%)$ & $13(2.4 \%)$ & $5(3.1 \%)$ & $1(4.5 \%)$ & $19(2.6 \%)$ \\
\hline SCAD & $0(0.0 \%)$ & $3(0.6 \%)$ & $2(1.3 \%)$ & $0(0.0 \%)$ & $5(0.7 \%)$ \\
\hline Other & $10(2.2 \%)$ & $20(3.7 \%)$ & $6(3.8 \%)$ & $3(13.6 \%)$ & $29(4.0 \%)$ \\
\hline \multicolumn{6}{|l|}{ Cardiovascular risk factors } \\
\hline Hypertension & $258(57.0 \%)$ & $314(58.0 \%)$ & $96(60.4 \%)$ & $13(54.2 \%)$ & $423(58.4 \%)$ \\
\hline Family history & $193(42.7 \%)^{* * *}$ & 300 (55.7\%)‡ & $70(43.8 \%) \neq$ & $14(58.3 \%)$ & $384(53.1 \%) \dagger$ \\
\hline Dyslipidemia & $241(53.1 \%)$ & $273(50.7 \%)$ & 77 (48.1\%) & $12(50.0 \%)$ & 362 (50.1\%) \\
\hline Diabetes & $116(25.6 \%)$ & $128(23.7 \%)$ & 46 (28.9\%) & $6(25.0 \%)$ & $180(24.9 \%)$ \\
\hline \multicolumn{6}{|l|}{ Comorbidities } \\
\hline Sleep apnea & $91(20.0 \%)^{*}$ & 76 (14.0\%) & $19(11.9 \%)$ & $4(16.7 \%)$ & 99 (13.6\%) \\
\hline Osteoarthritis & $24(5.3 \%)^{* * *}$ & 72 (13.3\%) & $26(16.3 \%)$ & $6(25.0 \%)$ & 104 (14.3\%) \\
\hline Cancer & $24(5.3 \%)^{* *}$ & $56(10.3 \%)$ & 15 (9.4\%) & $3(12.5 \%)$ & 74 (10.2\%) \\
\hline
\end{tabular}

$\mathrm{N}(\%)$ or mean \pm standard deviation shown

$\mathrm{CABG}=$ coronary artery bypass graft; $\mathrm{CAD}=$ coronary artery disease $\mathrm{CR}=$ cardiac rehabilitation; $\mathrm{MI}=$ myocardial infarction; $\mathrm{N}=$ sample size; $\mathrm{PCl}=$ percutaneous coronary intervention; PVD = peripheral vascular disease; SCAD = spontaneous coronary artery dissection; TIA = transient ischemic attack

${ }^{*}$ Mann-Whitney $U$ or chi-square test for difference between men and women in mixed-sex model: ${ }^{*} P<.05,{ }^{* *} P<.01,{ }^{* * *} P<.001$

${ }^{\dagger}$ Kruskal-Wallis or chi-square test for difference between model among women: $\uparrow P<.05 ; \uparrow+P<.01 ; \dagger+\uparrow P<.001$

${ }^{\ddagger}$ Post-hoc test results, where above significant: $¥ P<.05 ; \neq \neq P<.01 ; \neq \neq \ddagger P<.001$

$\S$ Main referral event or procedure for each participant; in women, comparisons were only between supervised models due to low sample size in home-based 
in total. Their sociodemographic and clinical characteristics are shown in Table 1; other referral indications were primarily aneurysm, congenital heart disease, and heart transplant. Ninety-nine (14.2\%) women had elevated SBP, 39 (5.6\%) elevated DBP, 264 (48.4\%) LDL-C above target, 390 (55.9\%) waist circumference above target, and 152 (36.9\%) elevated depressive symptoms at baseline.

With regard to differences in outcomes at baseline in women in the supervised programs (Table 3), cardiorespiratory fitness was significantly higher in women in mixed-sex compared to those in women-only $(P=0.007$ and $P=0.006$ for $\mathrm{VO}_{2 \text { peak }}$ and METs, respectively). No other differences were observed, however caution is warranted in interpreting the home-based data given the small sample size of retained participants.

Compared to the matched sample of men (Table 1), significantly less women in the supervised mixed-sex model were married or in a common-law relationship $(P<0.001)$, and lived with a spouse or partner $(P<0.001)$. In terms of clinical characteristics, PCI was a more common referral procedure in men $(P<0.001)$, while valvular heart disease $(P=0.015)$, primary prevention $(P<0.001)$, and myocardial infarction $(P=0.004)$ were more common in women $(P<0.001)$; family history was a more common CVD risk factor in women than men $(P<0.001)$. As for comorbidities, the proportion of sleep apnea in men was significantly higher than in women $(P=0.022)$, while the proportions of osteoarthritis and cancer were higher in women compared to men $(P<0.001$ and $P=0.003$, respectively). No other differences were observed (as per matching, there were no differences in age or CABG).

Compared to matched men pre-CR, cardiorespiratory fitness $\left(P<0.001\right.$ for both $\mathrm{VO}_{2 \text { peak }}$ and METs) were significantly lower in women, while total cholesterol $(P=0.005)$, triglycerides $(P=0.007)$, HDL-C $(P<0.001)$, and depressive symptoms $(P<0.001)$ were significantly higher in women (Table 4).

\section{Outcomes}

Differences in sociodemographic and clinical characteristics of those women who completed outcome assessments versus those who did not are shown in Table 2. As shown, with regard to sociodemographic characteristics, the proportion of retained female participants who spoke English as their first language was significantly greater than among those who dropped out. With regard to clinical characteristics, the proportion of retained female participants who had dyslipidemia was significantly greater than among those who dropped out. No other differences were observed. In matched men, compared to those lost to follow-up, there was a higher proportion of men with CABG among those who completed CR $(n=32,11.3 \%$ vs. $\mathrm{n}=9,5.3 \% ; P=0.031$ ), while the proportion of men with arrhythmia/rhythm device $(\mathrm{n}=14,8.3 \%$ vs $\mathrm{n}=7$, $2.5 \% ; P=0.005)$ was higher among those who dropped out than those who completed. No other differences were observed (data not shown).

Table 3 displays outcome scores by model at each assessment point. Tobacco use was negligible. Post-program, among completers, 311 (90.4\%) and 339 (98.5\%) women had SBP and DBP under the guideline-recommended target of 140/90 $\mathrm{mmHg}$, respectively; 160 (52.3\%) women reached the guideline-recommended target for LDL-C of $1.8 \mathrm{mmol} / \mathrm{L}$, and 195 (54.9\%) women had a waist circumference of $\leq 88 \mathrm{~cm}$. In terms of depressive symptoms, 207 (77.8\%) women did not have elevated CES-D scores. These proportions did not differ significantly by model among women, but again caution is warranted in interpreting the home-based data given the small sample of retained participants.

As also shown in Table 3, among women, cardiorespiratory fitness significantly improved with mixed-sex and women-only CR (supervised models). With regard to cardiovascular risk factors, HDL-C and waist circumference significantly improved in mixed-sex. With regard to psychosocial outcomes, depressive symptoms and quality of life significantly improved in mixed-sex. No other changes were observed; there was low power for homebased, but what would be considered a clinically-significant reduction in SBP was observed.

As also shown in Table 3, between-group differences in women were assessed, but the home-based participants were excluded due to the small sample size postprogram. Results showed that after adjusting for intake values, cardiorespiratory fitness was significantly greater with mixed-sex than women-only $\mathrm{CR}$ (for $\mathrm{VO}_{2 \text { peak: }}$ : estimate $=1.67$, standard error $[\mathrm{SE}]=0.63,95 \%$ Confidence Interval $[\mathrm{CI}] 0.43$ to 2.91 ; for METS: estimate $=0.51$, $\mathrm{SE}=0.18,95 \%$ CI 0.15 to 0.86 ). There were no significant differences in other clinical outcomes post-CR by supervised model; there was a trend favoring mixed-sex for SBP. Visual inspection of the home-based data suggests cardiorespiratory fitness, blood pressure, and HDL-C may be lower at discharge, while cholesterol, waist circumference and BMI higher than in the supervised models.

When examining sex differences in outcomes in the supervised mixed-sex program (Tables 3, 4), general linear mixed models adjusting for baseline values revealed cardiorespiratory fitness $\left(P<0.001\right.$ for both $\mathrm{VO}_{2 \text { peak }}$ and METs), and quality of life $(P=0.002)$ were significantly lower in women, while triglycerides $(P=0.014)$, HDL-C $(P<0.001)$, LDL-C $(P<0.001)$, and depressive symptoms $(P<0.001)$ were significantly higher in women compared to men. 
Table 2 Women's pre-CR characteristics by retention status, $N=727$

\begin{tabular}{|c|c|c|c|}
\hline & $\begin{array}{l}\text { Retained/Completed } \\
\mathrm{N}=428(58.9 \%)\end{array}$ & $\begin{array}{l}\text { Lost to follow-up/Dropouts } \\
\mathrm{N}=299(41.1 \%)\end{array}$ & $P$ value* \\
\hline \multicolumn{4}{|l|}{ Sociodemographic } \\
\hline Age & $67.5 \pm 11.7$ & $65.9 \pm 13.1$ & .148 \\
\hline Marital status (\% married/common-law) & $201(68.4)$ & $132(64.1)$ & .317 \\
\hline Highest educational attainment ( $\% \geq$ high school) & $247(94.3)$ & $143(90.5)$ & .146 \\
\hline Language spoken (\% English) & $328(98.2)$ & $214(94.7)$ & .021 \\
\hline Occupational status & & & .067 \\
\hline Retired/no formal employment & $185(66.3)$ & $115(68.9)$ & - \\
\hline Full-time/part-time/modified/restricted duties & $84(30.1)$ & $39(23.4)$ & - \\
\hline Other (e.g., disability) & $10(3.6)$ & $13(7.8)$ & - \\
\hline Travel time to CR centre (\% 0-30 min) & $104(56.5)$ & $75(66.4)$ & .092 \\
\hline Living situation & & & .229 \\
\hline With spouse/partner & $165(52.4)$ & $91(46.2)$ & - \\
\hline Alone & $100(31.7)$ & $64(32.5)$ & - \\
\hline With family/friends/others & $50(15.9)$ & $42(21.3)$ & - \\
\hline \multicolumn{4}{|l|}{ Clinical } \\
\hline Referral event/procedure§ & & & .217 \\
\hline $\mathrm{PCl}$ & $158(37.3)$ & $88(29.8)$ & - \\
\hline Valvular heart disease & $49(11.6)$ & $34(11.5)$ & - \\
\hline CABG & $45(10.6)$ & $27(9.2)$ & - \\
\hline Stroke/TIA & $39(9.2)$ & $28(9.5)$ & - \\
\hline Primary prevention & $30(7.1)$ & $22(7.5)$ & - \\
\hline Arrhythmia/Rhythm device & $25(5.9)$ & $24(8.1)$ & - \\
\hline Heart failure & $9(2.1)$ & $17(5.8)$ & - \\
\hline Angina pectoris (stable/unstable) & $12(2.8)$ & $13(4.4)$ & - \\
\hline Cardiomyopathy & $13(3.1)$ & $11(3.7)$ & - \\
\hline $\mathrm{Ml}$ & $16(3.8)$ & $6(2.0)$ & - \\
\hline PVD & $11(2.6)$ & $8(2.7)$ & - \\
\hline SCAD & $3(0.7)$ & $2(0.7)$ & - \\
\hline Other & $14(3.3)$ & $15(5.1)$ & - \\
\hline \multicolumn{4}{|l|}{ Cardiovascular risk factors } \\
\hline Hypertension & $251(58.9)$ & $172(57.7)$ & .747 \\
\hline Family history of CVD & $237(55.9)$ & $147(49.2)$ & .074 \\
\hline Dyslipidemia & $229(54.0)$ & $133(44.6)$ & .013 \\
\hline Diabetes & $95(22.3)$ & 85 (28.6) & .053 \\
\hline \multicolumn{4}{|l|}{ Comorbidities } \\
\hline Sleep apnea & $50(11.7)$ & $49(16.4)$ & .069 \\
\hline Osteoarthritis & $65(15.2)$ & $39(13.0)$ & .417 \\
\hline Cancer & $42(9.8)$ & $32(10.7)$ & .696 \\
\hline
\end{tabular}

$\mathrm{N}(\%)$ or mean \pm standard deviation shown

$\mathrm{CABG}=$ coronary artery bypass graft; $\mathrm{CAD}=$ coronary artery disease; $\mathrm{CR}=$ cardiac rehabilitation; $\mathrm{MI}=$ myocardial infarction; $\mathrm{N}=$ sample size; $\mathrm{PCl}=$ percutaneous coronary intervention; $\mathrm{PVD}=$ peripheral vascular disease; $\mathrm{SCAD}=$ spontaneous coronary artery dissection; TIA = transient ischemic attack

*Mann-Whitney $\mathrm{U}$ or chi-square test for difference between retained/completed and lost to follow-up/dropouts

${ }^{\S}$ Main referral event or procedure for each participant

\section{Discussion}

This novel study has examined women's outcomes in all available CR models. While caution is warranted due to generalizability limits, the small sample of women completing the home-based model, and because the women-only program was not gender-tailored per se [23], contrary to hypotheses, the benefit of women-only CR was not evident. Outcome data suggested supervised 


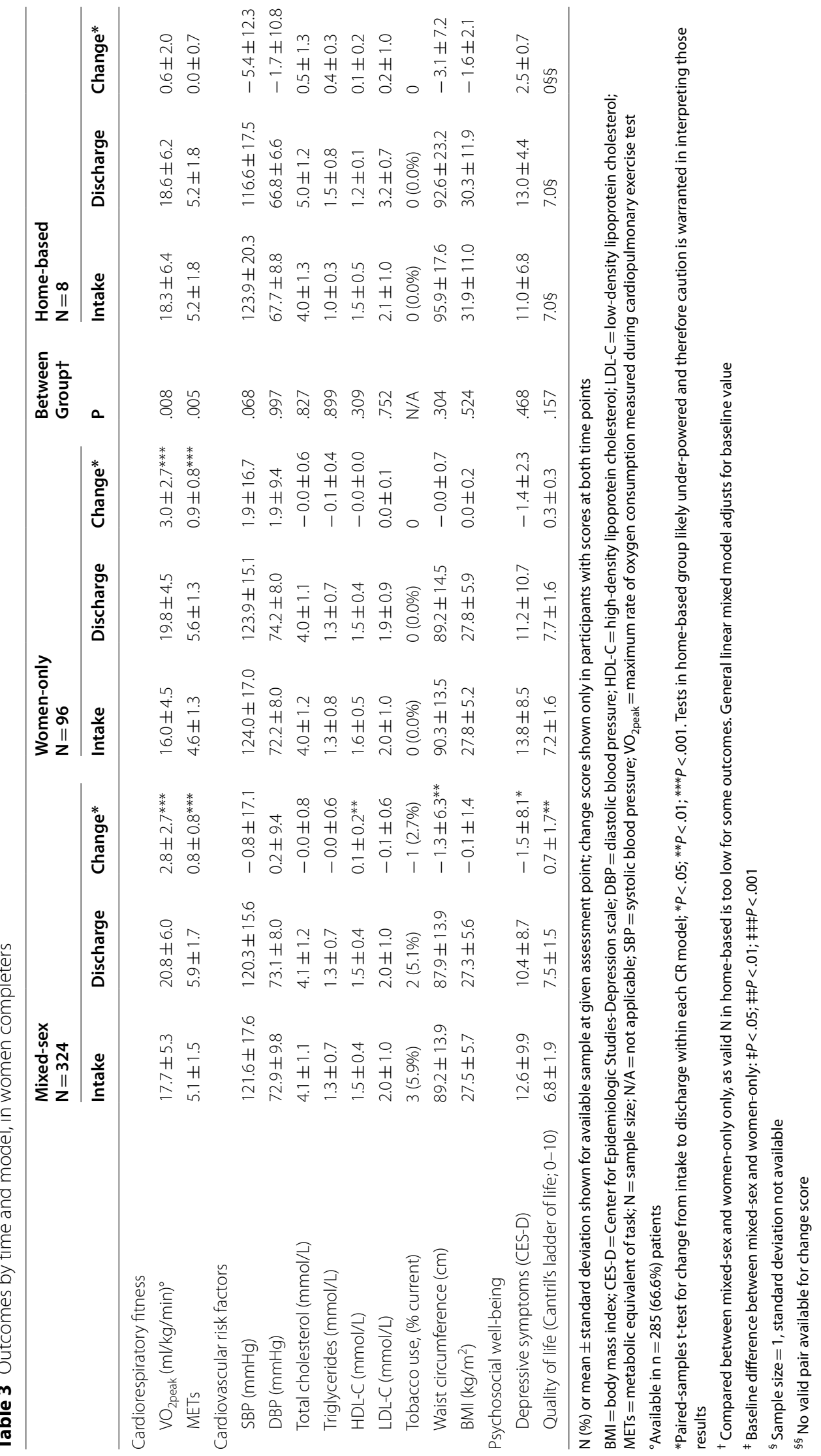


Table 4 Outcomes by time in matched, completing men in mixed-sex model, and difference from women in mixed-sex model

\begin{tabular}{|c|c|c|c|c|c|c|c|}
\hline & \multicolumn{3}{|l|}{$\begin{array}{l}\text { Men } \\
\mathrm{N}=\mathbf{2 8 3}\end{array}$} & \multirow[t]{2}{*}{$\begin{array}{l}\text { Intake sex difference } \\
\mathrm{N}=270\end{array}$} & \multicolumn{3}{|c|}{ Sex difference over 6 months‡ } \\
\hline & Intake & Discharge & Change* & & Estimate & SE & 95\% Cl (Lower, Upper) \\
\hline \multicolumn{8}{|l|}{ Cardiorespiratory fitness } \\
\hline $\mathrm{VO}_{2 \text { peak }}(\mathrm{ml} / \mathrm{kg} / \mathrm{min})$ & $21.8 \pm 6.6$ & $26.4 \pm 8.2$ & $4.4 \pm 4.7^{* * *}$ & $-4.5 \pm 7.2^{* * *}$ & $-4.80^{* * *}$ & 0.35 & $-5.49,-4.12$ \\
\hline METs & $6.3 \pm 1.9$ & $7.5 \pm 2.4$ & $1.2 \pm 1.4^{* * *}$ & $-1.4 \pm 2.1^{* * *}$ & $-1.39^{* * *}$ & 0.10 & $-1.58,-1.19$ \\
\hline \multicolumn{8}{|l|}{ Cardiovascular risk factors } \\
\hline $\mathrm{SBP}(\mathrm{mmHg})$ & $119.5 \pm 16.2$ & $120.6 \pm 16.2$ & $1.2 \pm 17.1$ & $0.9 \pm 23.0$ & 0.37 & 0.97 & $-1.53,2.28$ \\
\hline $\mathrm{DBP}(\mathrm{mmHg})$ & $72.1 \pm 10.5$ & $72.7 \pm 9.2$ & $0.3 \pm 10.7$ & $1.1 \pm 14.6$ & 0.77 & 0.61 & $-0.43,1.97$ \\
\hline Total cholesterol (mmol/L) & $3.4 \pm 1.0$ & $3.5 \pm 0.9$ & $0.1 \pm 0.7$ & $0.5 \pm 2.5^{* *}$ & 0.67 & 0.07 & $0.54,0.80$ \\
\hline Triglycerides (mmol/L) & $1.3 \pm 0.7$ & $1.2 \pm 0.6$ & $-0.1 \pm 0.5$ & $0.2 \pm 1.0^{* *}$ & $0.11^{*}$ & 0.05 & $0.02,0.20$ \\
\hline $\mathrm{HDL}-\mathrm{C}(\mathrm{mmol} / \mathrm{L})$ & $1.2 \pm 0.3$ & $1.3 \pm 0.3$ & $0.1 \pm 0.2^{* * *}$ & $0.3 \pm 0.5^{* * *}$ & $0.28^{* * *}$ & 0.24 & $0.23,0.33$ \\
\hline $\mathrm{LDL}-\mathrm{C}(\mathrm{mmol} / \mathrm{L})$ & $1.7 \pm 0.8$ & $1.7 \pm 0.7$ & $-0.0 \pm 0.6$ & $0.2 \pm 2.4$ & $0.33^{* * *}$ & 0.05 & $0.22,0.43$ \\
\hline Tobacco use, (\% current) & $5(10.6 \%)$ & $3(10.3 \%)$ & $-2(7.1 \%)$ & $3(3.3 \%)$ & N/A & N/A & N/A \\
\hline Waist circumference (cm) & $97.2 \pm 12.1$ & $95.8 \pm 12.5$ & $-1.5 \pm 5.1^{* * *}$ & N/A & N/A & N/A & N/A \\
\hline BMI $\left(\mathrm{kg} / \mathrm{m}^{2}\right)$ & $27.6 \pm 4.5$ & $27.4 \pm 4.7$ & $-0.3 \pm 1.5^{* *}$ & $0.4 \pm 7.8$ & -0.21 & 0.31 & $-0.81,0.40$ \\
\hline \multicolumn{8}{|l|}{ Psychosocial well-being } \\
\hline Depressive symptoms (CES-D) & $9.7 \pm 8.1$ & $8.2 \pm 7.5$ & $-1.7 \pm 6.0^{* *}$ & $4.8 \pm 12.9^{* * *}$ & $3.39^{* * *}$ & 0.63 & $2.16,4.63$ \\
\hline $\begin{array}{l}\text { Quality of life (Cantril's ladder of } \\
\text { life) }\end{array}$ & $7.1 \pm 1.7$ & $7.4 \pm 1.5$ & $0.6 \pm 1.5^{* *}$ & $-0.4 \pm 2.5$ & $-0.48^{* *}$ & 0.16 & $-0.79,-0.18$ \\
\hline
\end{tabular}

$\mathrm{N}(\%)$ or mean \pm standard deviation shown

$\mathrm{BMI}=$ body mass index; $\mathrm{CES}-\mathrm{D}=$ Center for Epidemiologic Studies-Depression scale; $\mathrm{Cl}=$ confidence interval; $\mathrm{DBP}=$ diastolic blood pressure; $\mathrm{HDL}-\mathrm{C}=$ high-density lipoprotein cholesterol; LDL-C=low-density lipoprotein cholesterol; METs=metabolic equivalent of task; $N=$ sample size; $N / A=$ not applicable (i.e., sample size too small to run general linear mixed model, or not appropriate to test for sex differences in waist circumference due to biological differences); SBP $=$ systolic blood pressure; $\mathrm{SE}=$ standard error; $\mathrm{VO}_{2 \text { peak }}=$ maximum rate of oxygen consumption measured during cardiopulmonary exercise test

*Paired-samples t-test for change from intake to discharge in men; ${ }^{*} P<.05 ;{ }^{*} P<.01 ;{ }^{* * *} P<.001$

${ }^{\dagger}$ Paired-samples t-test for baseline difference between women and men (matched), men as reference category

${ }^{\ddagger}$ General linear mixed model for sex difference; estimates for women with men as reference category

CR resulted in greater cardiorespiratory fitness, with significant improvements from pre to post-program in risk factors and psychosocial well-being in mixed-sex participants only.

\section{Outcomes}

An improvement of $1 \mathrm{ml} / \mathrm{kg} / \mathrm{min}$ in $\mathrm{VO}_{2 \text { peak }}$ is associated with $9-15 \%$ risk reduction in cardiac and overall mortality, both in men and women, and a 0.5 MET increase is associated with significantly lower mortality [42-45]. In this study, the improvement in cardiorespiratory fitness was clinically-meaningful in women in mixed-sex and women-only CR (i.e., the supervised models), but not in home-based (although caution is warranted due to the small sample size).

The somewhat greater utilization rates in the mixedsex likely translated to the significantly greater functional capacity in women attending that model, although the higher fitness at intake likely also played a role; there was also a trend towards lower SBP with mixed-sex compared to women-only. Moreover, the greater utilization may have resulted in the significant increase in HDL-C and quality of life as well as reduction in depressive symptoms with mixed-sex, which were not observed with womenonly. It was unexpected that the women-only model did not result in improved psychosocial well-being as has been observed with the 2 women-only CR RCTs [46-48]. Overall, clearly women-only did not result in better outcomes in this study as hypothesized.

\section{Sex differences}

Consistent with literature $[49,50]$, women did come to $\mathrm{CR}$ with a poorer clinical profile than men. Women presented with poorer functional capacity, and had a poorer risk factor profile, but then they do have more to gain. Also consistent with literature, they were older, had less spousal support, different cardiac indications (i.e., women treated less aggressively), and more comorbidities [51]. Both women and men in supervised CR achieved significant improvements in cardiorespiratory fitness, again an indicator closely associated with mortality [45], but this was greater in men as shown in the literature. Quality of life was also better in men, with also lower 
lipids and depressive symptoms, even with adjustment for intake values. It is disheartening that we still have not closed this chasm in men's and women's outcomes, and based on this paper, women-only CR does not appear to be the answer we hoped it to be.

\section{Implications and research directions}

The results of this study suggest there might not be enough benefit of a women-only model that is not gender-tailored to warrant the resources needed; indeed there is limited controlled research in this area and hence not a large body of high-quality evidence to inform policy and CR care provision decisions at the program-level $[23,28]$. Given the limited sample and generalizability, it is premature to draw conclusions regarding whether women-only CR can address gender bias in CVD secondary prevention. Further research should consider whether offering some tailored women-only sessions might be engaging and cost-efficient [22]. Perhaps we should also be better at standardizing what gender-tailoring is desired by women in practice as well as what can lead to increased program engagement, and subsequently then better outcomes.

Despite the many constraints women have to coming on-site, results of this study also suggest we need to question and investigate whether women adhere and push themselves to achieve outcome improvements in unsupervised settings to the same degree. With such little post-program data in this cohort this is difficult to test however. More research is needed, preferably with a randomized design, comparing these outcomes in women participating in supervised and unsupervised models.

\section{Limitations}

Caution is warranted when interpreting these findings due to several study limitations. Chiefly, generalizability is limited due to the fact that the study was conducted at one academic health science centre, so the women-only offerings may be different than at other centres. Moreover, the $C R$ programs in this study offer a fairly high dose of CR compared to other jurisdictions [22], which may impact outcomes. Finally, most women-only programs are offered in the Eastern Mediterranean region [22]; it is likely these results are not generalizable to that setting.

Second, there was some retention bias for the third objective, approximately $40 \%$ of participants did not attend their discharge assessment, and this did vary by program model $[16,41]$. Women's high rate of CR dropout is well-documented in the literature. Third, the sample size in home-based was small, and this is compounded by the low retention mentioned above, rendering analyses likely under-powered. Hence, some outcome changes in the third objective could not be assessed due to the lack of available data; there may be differences not identified by this study, so more research is warranted.

Fourth, multiple comparisons were performed, which can increase error rates. Fifth, there are challenges associated with using administrative data; missing and implausible values were checked against hard charts at the beginning, but due to COVID-19 we could not check all values. Sixth, with regard to measurement, best practices in blood pressure assessment were not followed, and thus there is likely some error. Seventh, individual exercise prescriptions were not compared between models, and therefore superiority of the mixed-sex model due to greater exercise dose cannot be ruled out.

Finally, the study design was not randomized. Causal conclusions cannot be drawn. Furthermore, participants electing women-only CR were more often not in formal employment and were less likely to have a family history of CVD than those choosing mixed-sex CR. There were no significant differences for many other sociodemographic and clinical characteristics, but again due to design, the impact of selection bias on outcomes cannot be known.

\section{Conclusion}

Participants in mixed-sex only achieved significant improvements in HDL-C, waist circumference, quality of life, and depressive symptoms by program end; Fitness was significantly greater with mixed-sex than womenonly. The study was under-powered to make comparisons to home-based, but improvements in cardiorespiratory fitness require more study. Whether fully gender-tailored programs are advantageous requires more controlled, large-scale investigation. We need to better engage women in all models of $\mathrm{CR}$, to ensure they achieve optimal outcomes.

\section{Abbreviations}

CR: Cardiac rehabilitation; $\mathrm{VO}_{2}$ : Volume of oxygen consumed per unit of time; CVD: Cardiovascular disease; PCl: Percutaneous coronary intervention; CABG: Coronary artery bypass surgery; UHN: University Health Network; CAD: Coronary artery disease; METs: Metabolic equivalent of task; SBP: Systolic blood pressure; DBP: Diastolic blood pressure; LDL-C: Low density lipoprotein cholesterol; CES-D: Centre for epidemiologic studies-depression scale; SD: Standard deviation; HDL-C: High density lipoprotein cholesterol; BMI: Body mass index; RCT: Randomized controlled trial.

\section{Acknowledgements}

The authors thank Joan Kitchen, Sylvia Maksymiu, Merrisa Martinuzzi, Dr. Fernando Rivera Theurel, Marcella Calouro, Emily Joseph, Shital Shah, Lauren Jenkinson, Madeleine Flores-Hukom, Karen Dobson, Priscilla Gonsalves, Betty Chau, Holly Wykes, Ray Vickers, and Lucy Moniz, for sharing their expertise regarding model delivery and/or role in delivering women-only $C R$ at the study sites. We also thank Dr. Hugh McCague, Dr. Robert Cribbie, and Mirka Ondrak for statistical advice. 


\section{Authors' contributions}

SLG and PO conceived the study. TC and RN developed the women-only model; PO is the medical director. FH extracted and cleaned data, as well as performed statistical analyses; SLG and SM supervised the first author trainee. FH and SLG drafted the manuscript, and all other authors revised it critically for important intellectual content. SLG and FH are responsible for the overall content as guarantors. The corresponding author attests that all listed authors meet authorship criteria, and that no others meeting the criteria have been omitted. All authors read and approved the final manuscript.

\section{Funding}

SLG is supported in her work by the Toronto General \& Toronto Western Hospital Foundation and the Peter Munk Cardiac Centre, University Health Network, Toronto, Canada.

\section{Availability of data and materials}

Due to the nature of this research, participants of this study did not agree for their data to be shared publicly, so supporting data cannot not be made publicly available. Data are available upon request to the corresponding author by qualified investigators with appropriate approvals.

\section{Declarations}

\section{Ethics approval and consent to participate}

All methods were performed in accordance with the relevant guidelines and regulations. Institutional research ethics board approval was obtained from University Health Network's Research Ethics Board (\#20-6035), and the study was granted an exemption from requiring informed consent by the same ethics board.

\section{Consent for publication}

Not applicable.

\section{Competing interests}

The authors declare that they have no competing interest.

\section{Author details}

${ }^{1}$ Faculty of Health, York University, Bethune 368, 4700 Keele Street, Toronto, ON M3J 1P3, Canada. ${ }^{2}$ KITE-Toronto Rehabilitation Institute, University Health Network, University of Toronto, Toronto, ON, Canada.

Received: 16 June 2021 Accepted: 26 November 2021 Published online: 15 December 2021

\section{References}

1. Institute for Health Metrics and Evaluation (IHME). GBD Results Too [Internet]. IHME, University of Washington. Seattle, WA: IHME, University of Washington; 2021 [cited 2021 Sep 16]. http://ghdx.healthdata.org/gbdresults-tool

2. Norris CM, Yip CYY, Nerenberg KA, Clavel M, Pacheco C, Foulds HJA, et al. State of the science in women's cardiovascular disease: a canadian perspective on the influence of sex and gender. J Am Heart Assoc. 2020;9:e015634.

3. Wenger NK. You've come a long way, baby. Circulation. 2004;109(5):558-60.

4. Mehta LS, Beckie TM, DeVon HA, Grines CL, Krumholz HM, Johnson MN, et al. Acute myocardial infarction in women: a scientific statement from the American Heart Association. Circulation. 2016;133(9):916-47.

5. Francis T, Kabboul N, Rac V, Mitsakakis N, Pechlivanoglou P, Bielecki J, et al. The effect of cardiac rehabilitation on health-related quality of life in patients with coronary artery disease: a meta-analysis. Can J Cardiol. 2019;35:352-64.

6. Anderson L, Oldridge N, Thompson DR, Zwisler A-D, Rees K, Martin N, et al. Exercise-based cardiac rehabilitation for coronary heart disease: cochrane systematic review and meta-analysis. J Am Coll Cardiol. 2016:67(1):1-12

7. Kabboul N, Tomlinson G, Francis T, Grace S, Chaves G, Rac V, et al. Comparative effectiveness of the core components of cardiac rehabilitation on mortality and morbidity: a systematic review and network meta-analysis. J Clin Med. 2018;7(12):514.

8. Ghisi GL, Chaves GS, Bennett A, Lavie CJ, Grace SL. The effects of cardiac rehabilitation on mortality and morbidity in women: a meta-analysis attempt. J Cardiopulm Rehabil Prev. 2019:39(1):39-42.

9. Colbert JD, Martin BJ, Haykowsky MJ, Hauer TL, Austford LD, Arena RA, et al. Cardiac rehabilitation referral, attendance and mortality in women. Eur J Prev Cardiol. 2015;22(8):979-86.

10. De Souza E, Silva CG, Nishijuka FA, De Castro CLB, Franca JF, Myers J, Laukkanen JA, et al. Women have lower mortality than men after attending a long-term medically supervised exercise program. J Cardiopulm Rehabil Prev. 2021. https://doi.org/10.1097/HCR.0000000000000623.

11. Daniels KM, Arena R, Lavie CJ, Forman DE. Cardiac rehabilitation for women across the lifespan. Am J Med. 2012;125(9):937.e1-7.

12. Engberding N, Wenger NK. Cardiac rehabilitation for women. Curr Cardiovasc Risk Rep. 2013;7(3):203-11.

13. Budnick K, Campbell J, Esau L, Lyons J, Rogers N, Haennel RG. Cardiac rehabilitation for women: a systematic review. Can J Cardiovasc Nurs. 2009;19(4):13-25.

14. Mosca L, Benjamin EJ, Berra K, Bezanson JL, Dolor RJ, Lloyd-Jones DM, et al. Effectiveness-based guidelines for the prevention of cardiovascular disease in women-2011 update. Circulation. 2011;123(11):1243-62.

15. Santiago de Araújo Pio C, Beckie TM, Varnfield M, Sarrafzadegan N, Babu AS, Baidya S, et al. Promoting patient utilization of outpatient cardiac rehabilitation: a joint International Council and Canadian Association of Cardiovascular Prevention and Rehabilitation position statement. Int J Cardiol. 2020;298:1-7.

16. Oosenbrug E, Marinho RP, Zhang J, Marzolini S, Colella TJF, Pakosh M, et al Sex differences in cardiac rehabilitation adherence: a meta-analysis. Can J Cardiol. 2016;32(11):1316-24.

17. Samayoa L, Grace SL, Gravely S, Scott LB, Marzolini S, Colella TJF. Sex differences in cardiac rehabilitation enrollment: a meta-analysis. Can J Cardiol. 2014;30(7):793-800

18. Colella TJ, Gravely S, Marzolini S, Grace SL, Francis JA, Oh P, et al. Sex bias in referral of women to outpatient cardiac rehabilitation? A meta-analysis. Eur J Prev Cardiol. 2015;22(4):423-41.

19. Supervía M, Medina-Inojosa JR, Yeung C, Lopez-Jimenez F, Squires RW, Pérez-Terzic CM, et al. Cardiac rehabilitation for women: a systematic review of barriers and solutions. Mayo Clin Proc. 2017;92(4):565-77.

20. Grace SL, Gravely-Witte S, Kayaniyil S, Brual J, Suskin N, Stewart DE. A multisite examination of sex differences in cardiac rehabilitation barriers by participation status. J Women's Heal. 2009:18(2):209-16.

21. Price J, Landry M, Rolfe D, Delos-Reyes F, Groff L, Sternberg L. Women's cardiac rehabilitation: improving access using principles of women's health. Can J Cardiovasc Nurs. 2005;15(3):32-41.

22. Turk-Adawi K, Supervia M, Lopez-Jimenez F, Adawi A, Sadeghi M, Grace SL. Women-only cardiac rehabilitation delivery around the world. Heart Lung Circ. 2021;30(1):135-43.

23. Mamataz T, De Melo Ghisi GL, Pakosh M, Grace SL. Nature, availability and utilization of women-focused cardiac rehabilitation: a systematic review. BMC Cardiovasc Disord. 2021. https://doi.org/10.1186/ s12872-021-02267-0.

24. Thomas RJ, Beatty AL, Beckie TM, Brewer LPC, Brown TM, Forman DE, et al. Home-based cardiac rehabilitation: a scientific statement from the american association of cardiovascular and pulmonary rehabilitation, the american heart association, and the american college of cardiology. Circulation. 2019;140(1):E69-89.

25. Andraos C, Arthur HM, Oh P, Chessex C, Brister S, Grace SL. Women's preferences for cardiac rehabilitation program model: a randomized controlled trial. Eur J Prev Cardiol. 2015:22(12):1513-22.

26. Grace SL, Racco C, Chessex C, Rivera T, Oh P. A narrative review on women and cardiac rehabilitation: program adherence and preferences for alternative models of care. Maturitas. 2010;67(3):203-8.

27. Anderson L, Sharp GA, Norton RJ, Dalal H, Dean SG, Jolly K, et al. Homebased versus centre-based cardiac rehabilitation. Cochrane Database Syst Rev. 2017:6(6):CD007130.

28. Mamataz T, De Melo Ghisi GL, Pakosh M, Grace SL. Outcomes and Cost of Women-focused Cardiac Rehabilitation: A Systematic Review and Metaanalysis. Maturitas. 2021; Under revision. 
29. Russell KL, Holloway TM, Brum M, Caruso V, Chessex C, Grace SL. Cardiac rehabilitation wait times: effect on enrollment. J Cardiopulm Rehabil Prev. 2011;31(6):373-7.

30. Dalleck LC, Tischendorf JS. Guidelines for exercise testing and prescription (ACSM) 10th edn. In: Riebe D, Ehrman JK, Liguori G, Magal M, editors. Encyclopedia of lifestyle medicine and health. Philadelphia: Wolters Kluwer; 2012. p. 183

31. Borg GAV. Psychophysical bases of perceived exertion. Med Sci Sport Exerc. 1982:14(5):377-81.

32. Marzolini S, Oh PI, Thomas SG, Goodman JM. Aerobic and resistance training in coronary disease: single versus multiple sets. Med Sci Sports Exerc. 2008;40(9):1557-64.

33. Ghisi GLM, Scane K, Sandison N, Maksymiu S, Skeffington V, Oh P. Development of an educational curriculum for cardiac rehabilitation patients and their families. J Clin Exp Cardiolog. 2015;06(05):1-13.

34. Scane K, Alter D, Oh P, Brooks D. Adherence to a cardiac rehabilitation home program model of care: a comparison to a well-established traditional on-site supervised program. Appl Physiol Nutr Metab. 2012;37(2):206-13.

35. Grace SL, Poirier P, Norris CM, Oakes GH, Somanader DS, Suskin N. PanCanadian development of cardiac rehabilitation and secondary prevention quality indicators. Can J Cardiol. 2014;30(8):945-8.

36. Rabi DM, McBrien KA, Sapir-Pichhadze R, Nakhla M, Ahmed SB, Dumanski SM, et al. Hypertension Canada's 2020 comprehensive guidelines for the prevention, diagnosis, risk assessment, and treatment of hypertension in adults and children. Can J Cardiol. 2020;36(5):596-624.

37. Williams B, Mancia G, Spiering W, Rosei EA, Azizi M, Burnier M, et al. ESC/ ESH guidelines for the management of arterial hypertension. Vol. 39. Eur Heart J. 2018;2018:3021-104.

38. Grundy SM, Stone NJ, Bailey AL, Beam C, Birtcher KK, Blumenthal RS, et al. AHA/ACC/AACVPR/AAPA/ABC/ACPM/ADA/AGS/APhA/ASPC/NLA/PCNA guideline on the management of blood cholesterol. J Am Coll Cardiol. 2019;73(24):e285-350.

39. Radloff LS. The CES-D scale: a self-report depression scale for research in the general population. Appl Psychol Meas. 1977;1(3):385-401.

40. Cantril $\mathrm{H}$. The pattern of human concern. New Brunswick: Rutgers University Press; 1965. p. 22-4.

41. Heald FA, Marzolini S, Colella TJF, Oh P, Nijhawan R, Grace SL. Women choosing mixed-sex women-only, and home-based cardiac rehabilitation models and impact on utilization. Women Heal. 2021; under revision.

42. Kavanagh T, Mertens DJ, Hamm LF, Beyene J, Kennedy J, Corey P, et al. Prediction of long-term prognosis in 12169 men referred for cardiac rehabilitation. Circulation. 2002;106(6):666-71.

43. Kavanagh T, Mertens DJ, Hamm LF, Beyene J, Kennedy J, Corey P, et al. Peak oxygen intake and cardiac mortality in women referred for cardiac rehabilitation. J Am Coll Cardiol. 2003;42(12):2139-43.

44. Keteyian SJ, Brawner CA, Savage PD, Ehrman JK, Schairer J, Divine G, et al. Peak aerobic capacity predicts prognosis in patients with coronary heart disease. Am Heart J. 2008;156(2):292-300.

45. Myers J, Prakash M, Froelicher V, Do D, Partington S, Atwood JE. Exercise capacity and mortality among men referred for exercise testing. $\mathrm{N}$ Engl J Med. 2002;346(11):793-801.

46. Midence L, Arthur HM, Oh P, Stewart DE, Grace SL. Women's health behaviours and psychosocial well-being by cardiac rehabilitation program model: a randomized controlled trial. Can J Cardiol. 2016;32(8):956-62.

47. Beckie TM, Beckstead JW. The effects of a cardiac rehabilitation program tailored for women on global quality of life: a randomized clinical trial. J Women's Heal. 2010;19(11):1977-85.

48. Beckie TM, Beckstead JW, Schocken DD, Evans ME, Fletcher GF. The effects of a tailored cardiac rehabilitation program on depressive symptoms in women: a randomized clinical trial. Int J Nurs Stud. 2011;48(1):3-12.

49. Terada T, Chirico D, Tulloch HE, Scott K, Pipe AL, Reed JL. Sex differences in psychosocial and cardiometabolic health among patients completing cardiac rehabilitation. Appl Physiol Nutr Metab. 2019;44(11):1237-45.

50. Cannistra LB, Balady GJ, O'Malley CJ, Weiner DA, Ryan TJ. Comparison of the clinical profile and outcome of women and men in cardiac rehabilitation. Am J Cardiol. 1992;69(16):1274-9.

51. Stehli J, Duffy SJ, Burgess S, Kuhn L, Gulati M, Chow C, et al. Sex disparities in myocardial infarction: biology or bias? Hear Lung Circ. 2021;30(1):18-26.

\section{Publisher's Note}

Springer Nature remains neutral with regard to jurisdictional claims in published maps and institutional affiliations.
Ready to submit your research? Choose BMC and benefit from:

- fast, convenient online submission

- thorough peer review by experienced researchers in your field

- rapid publication on acceptance

- support for research data, including large and complex data types

- gold Open Access which fosters wider collaboration and increased citations

- maximum visibility for your research: over $100 \mathrm{M}$ website views per year

At BMC, research is always in progress.

Learn more biomedcentral.com/submissions 